\title{
Morbidity and mortality pattern among neonates admitted to the general paediatric ward of a secondary health care centre in the Niger delta region of Nigeria
}

\author{
*Matthias Mariere Okposio ${ }^{1}$, O I Ighosewe ${ }^{1}$ \\ Sri Lanka Journal of Child Health, 2016; 45(2):84-89
}

\begin{abstract}
Introduction: In Nigeria's public hospitals, facilities for specialized neonatal care are few and available only in tertiary hospitals. However a greater number of neonates are delivered in the primary and secondary health care centres where these facilities are lacking. Thus, sick newborns are managed in the general paediatric ward along with other children and there is a likelihood of increased mortality in this group of neonates compared to those managed in standard neonatal units.
\end{abstract}

Objective: To determine morbidity and mortality pattern among neonates admitted to a general paediatric ward of a secondary health care facility.

Method: This was a prospective cross sectional study of neonatal admissions and mortalities from January 2012 to December 2013.

Result: A total of 655 neonates were admitted during the study period of which 68 were excluded. Of the 587 neonates analysed. 360 were males. The leading causes of admissions were neonatal sepsis, prematurity, perinatal asphyxia, haemorrhagic disease of the newborn and neonatal jaundice. There were $122(20.3 \%)$ deaths with a male: female ratio of 1.7:1. Neonatal jaundice, prematurity and birth asphyxia had the highest case fatality rate.

Conclusions: There were $20.3 \%$ deaths. The leading causes of admissions were neonatal sepsis, prematurity, perinatal asphyxia, haemorrhagic disease of the newborn and neonatal jaundice.

DOI: http://dx.doi.org/10.4038/sljch.v45i2.7981

(Key words: Neonate, mortality, general paediatric ward, Niger Delta)

${ }^{1}$ Consultant Paediatrician, Delta State University Teaching Hospital, Oghara Delta State, Nigeria

Correspondence: mattokmatok@yahoo.com

(Received on 21 May 2015: Accepted after revision on 17 July 2015)

The authors declare that there are no conflicts of interest

Personal funding was used for this project.

Open Access Article published under the Creative

Commons Attribution CC-BY cC (i) License.

\section{Introduction}

Globally, about $40 \%$ of children less than 5 years and $57 \%$ of infants who die are newborns. Of these between 25 and $50 \%$ die in the first 24 hours and $75 \%$ in the first week ${ }^{1-2}$. Tertiary hospitals in Nigeria have functional newborn units but this is not the case in most secondary health care facilities across the country. Thus, neonates born in primary and most secondary health facilities requiring any form of inpatient treatment are referred to tertiary hospitals or any other hospital within that vicinity with a functional newborn unit. However, due to financial constraints or perceived inconvenience of distant travel, some parents refuse referral of their newborns, and thus are offered the less than ideal option of managing their newborns in the general paediatric ward where children with other diseases are also treated. The general paediatric ward usually does not have specialised personnel in neonatology and is either not equipped or only has basic tools such as a phototherapy unit to manage neonates. Several studies have been done in the neonatal units of most Nigeria tertiary health centres to determine the pattern of newborn morbidity and mortality. The results of these studies showed a neonatal mortality ranging between $13 \%$ and $25.9 \%$ while the common causes of neonatal death included but were not limited to perinatal or birth asphyxia, jaundice, infections and prematurity $^{3-6}$. However, similar studies in neonates admitted and treated in the general paediatric ward are few and far between. A mortality record in a Kenyan hospital suggested that the mortality rate for neonates admitted into the general paediatric ward was higher than that in the newborn unit ${ }^{7}$.

\section{Objective}

This study was undertaken to document the mortality and morbidity pattern of neonates admitted into the general paediatric ward with a view to identifying areas that need improvement in order to optimize their care.

\section{Method}

This was a prospective cross-sectional study undertaken at Mariere Memorial Central Hospital located in Ughelli, a suburban city in the Niger Delta area of Nigeria and inhabited mainly by the Urhobo ethnic group. The hospital is a 170-bed secondary health care facility that provides specialist healthcare and serves as a referral centre 
for hospitals and clinics in neighbouring towns and villages. The paediatric ward is a 22-bed unit which provides care to children $0-17$ years requiring a range of medical care. Equipment available in the unit for neonatal services includes 2 functional phototherapy machines and 2 dysfunctional incubators. The personnel in the department include a consultant paediatrician, 2 medical officers, 2 house officers and 8 nurses. The average monthly patient load is 150 and nurse to patient ratio is $1: 11$ in the morning shifts and 1:22 during the afternoon and night shifts.

Neonates are admitted into the paediatric ward either directly from the obstetrics and gynaecology department or via referral from other hospitals and clinics. Any newborn whose weight is below $1500 \mathrm{~g}$ or who has a life threatening congenital malformation is referred to a tertiary hospital. Preterm infants above $1500 \mathrm{~g}$ were admitted into a designated part of the paediatric ward and kept warm by wrapping with a blanket and putting under a 200 watts bulb about $50-70 \mathrm{~cm}$ from the baby. Temperature measurement was done on a regular basis with an individualized thermometer while kangaroo mother care was commenced once the newborn became stable.

All newborns admitted from January 2012 to December 2013 were enrolled on a structured protocol, which included data on gestational age at birth, gender, mode of delivery, place of delivery, place of antenatal care, age at presentation, diagnosis and outcome. Other information recorded were mother's age, educational status, parity and marital status. Weight at admission was used rather than birth weight as a significant number of these neonates were born at home and came to the hospital several days later. For the purpose of this study, the diagnoses were grouped under the following headings: (i) Birth or perinatal asphyxia (ii) Prematurity (iii) Neonatal sepsis (iv) Neonatal jaundice (v) Neonatal tetanus (vi) Haemorrhagic disease of the newborn (vii) Congenital anomalies (viii) Others. Neonates classified as having birth or perinatal asphyxia, prematurity, neonatal sepsis and neonatal jaundice in this study are as described by Ezechukwu et $\mathrm{al}^{4}$.

Exclusion criteria adopted for this study involves neonates who were discharged against medical advice and those who were referred since their outcome was not known.

Ethical approval for this study was obtained from the Research and Ethics Committee of the Delta
State Ministry of Health and permission was obtained from the hospital management.

The data was entered into the Statistical Package for Social Sciences (SPSS version 16). Analysis of the data was done using descriptive and inferential statistics. Percentages, ratio and frequencies were derived and associations tested using Chi-square where appropriate. A p-value of $<0.05$ was considered significant.

\section{Results}

A total of 3593 children aged $0-17$ years were admitted during the study period, of which 655 $(18.2 \%)$ were neonates. Out of this number, 68 were excluded from the study (52 were discharged against medical advice and 16 were referred). As a result, only 587 neonates were included for the data analysis of which 360 were males and 227 were females giving a male to female ratio of $1.6: 1$. Most of the neonates were out born $(79.4 \%$ vs $20.6 \%)$. One hundred and ten $(18.7 \%)$ of the neonates were preterm with a mean gestational age of $35.6 \pm 3.9$ while $22(3.7 \%)$ were post term. In addition, there were $101(17.2 \%)$ low birth weight neonates out of which 62 were preterm and 39 were term small for gestational age. Most of the neonates were admitted after 24 hours of life with a mean age at admission of $5.7 \pm 5.9$ days. Almost a quarter of the neonates were delivered at home by traditional birth attendants. Other sociodemographic variables relating to the study population are shown on Table 1.

The leading causes of admission were neonatal sepsis $(43.3 \%)$, prematurity $(18.7 \%)$, perinatal asphyxia (18.2) and neonatal jaundice (12.4\%). Other morbidities that necessitated admission were haemorrhagic disease of the newborn, neonatal tetanus and congenital anomalies as shown on Table 2.

A total of 122 deaths were recorded during the study period accounting for $20.3 \%$ of the total neonatal admissions. Out of this number, 78 were males while 44 were females giving a male: female ratio of $1.7: 1$. However, there was no significant association between gender and mortality $\left(\chi^{2}\right.$ $=0.59, \mathrm{df}=1, \mathrm{p}=0.44)$. Majority of the deaths occurred in the first week of life $(81.2 \%)$ of which $59.4 \%$ took place in the first 24 hours following admission. The place of birth was strongly associated with mortality $\left(\chi^{2}=6.01\right.$, df $=1, p=$ $0.01)$. Mortality was highest among newborn who presented after 3 weeks of life, followed by those who presented within 24 hours of life, $30.8 \%$ and $27.6 \%$ respectively as shown in Table 3 . 
Table 1: Socio-demographic and maternal profile of study population $(\mathrm{n}=587)$

\begin{tabular}{|c|c|}
\hline Characteristic & Number (\%) \\
\hline $\begin{array}{l}\text { Sex } \\
\text { Male } \\
\text { Female }\end{array}$ & $\begin{array}{l}360(61.3) \\
227(38.7)\end{array}$ \\
\hline $\begin{array}{l}\text { Gestational age } \\
\text { Preterm } \\
\text { Term } \\
\text { Post term }\end{array}$ & $\begin{array}{c}110(18.7) \\
455(77.5) \\
22(03.7) \\
\end{array}$ \\
\hline $\begin{array}{l}\text { Birth weight } \\
\text { Low birth weight } \\
\text { Preterm } \\
\text { Term SGA } \\
\text { Normal birth weight } \\
\text { High birth weight }\end{array}$ & $\begin{array}{c}101(17.2) \\
62 \\
39 \\
416(70.9) \\
70(11.9) \\
\end{array}$ \\
\hline $\begin{array}{l}\text { Age at presentation } \\
\leq 24 \text { hours } \\
2-7 \text { days } \\
8-14 \text { days } \\
15-21 \text { days } \\
22-28 \text { days } \\
\end{array}$ & $\begin{array}{l}123(21.0) \\
339(57.8) \\
77(13.1) \\
35(06.0) \\
13(02.2) \\
\end{array}$ \\
\hline $\begin{array}{l}\text { Mode of Delivery } \\
\text { Vaginal delivery } \\
\text { Caesarean section }\end{array}$ & $\begin{array}{c}496(84.5) \\
91(15.5)\end{array}$ \\
\hline $\begin{array}{l}\text { Place of Delivery } \\
\text { Government hospital } \\
\text { Private hospital } \\
\text { Traditional birth attendant / Home }\end{array}$ & $\begin{array}{c}394(67.1) \\
58(09.9) \\
135(23.0) \\
\end{array}$ \\
\hline $\begin{array}{l}\text { Maternal Age } \\
\leq 20 \text { years } \\
21-30 \text { years } \\
31-40 \text { years } \\
\geq 41\end{array}$ & $\begin{array}{l}74(12.6) \\
326(55.5) \\
175(29.8) \\
12(02.0)\end{array}$ \\
\hline $\begin{array}{l}\text { Parity } \\
\text { Primipara } \\
\text { Multipara } \\
\text { Grand Multipara } \\
\end{array}$ & $\begin{array}{l}222(37.8) \\
279(47.5) \\
86(14.7) \\
\end{array}$ \\
\hline $\begin{array}{l}\text { Maternal educational status } \\
\text { None } \\
\text { Primary } \\
\text { Secondary } \\
\text { Tertiary }\end{array}$ & $\begin{array}{c}20(03.4) \\
155(26.4) \\
316(53.8) \\
96(16.4) \\
\end{array}$ \\
\hline $\begin{array}{l}\text { Maternal marital status } \\
\text { Married } \\
\text { Co-habiting } \\
\text { Single }\end{array}$ & $\begin{array}{l}297(50.6) \\
268(45.7) \\
22(03.7)\end{array}$ \\
\hline
\end{tabular}

Table 2: Morbidity pattern of study population $(\mathrm{n}=587)$

\begin{tabular}{|l|c|}
\hline \multicolumn{1}{|c|}{ Disease } & Number (\%) \\
\hline Neonatal sepsis & $254(43.3)$ \\
\hline Prematurity & $110(18.7)$ \\
\hline Birth asphyxia & $107(18.2)$ \\
\hline Neonatal jaundice & $73(12.4)$ \\
\hline Neonatal tetanus & $12(02.0)$ \\
\hline Haemorrhagic disease of newborn (HDNB) & $25(04.3)$ \\
\hline Congenital anomalies & $02(0.3)$ \\
\hline Others & $04(0.7)$ \\
\hline
\end{tabular}


Table 3: Outcome in relation to age at admissions

\begin{tabular}{|l|c|c|c|}
\hline \multirow{2}{*}{ Age at admission } & \multicolumn{2}{|c|}{ Outcome } & \multirow{2}{*}{$\begin{array}{c}\text { Total } \\
\text { Number (\%) }\end{array}$} \\
\cline { 2 - 3 } & Died Number (\%) & Discharged Number (\%) & $123(100)$ \\
\hline$\leq 1$ day & $34(27.6)$ & $89(72.4)$ & $339(100)$ \\
\hline $2-7$ days & $66(19.5)$ & $273(80.5)$ & $77(100)$ \\
\hline $15-21$ days & $11(14.3)$ & $66(85.7)$ & $35(100)$ \\
\hline $22-28$ days & $04(11.4)$ & $31(88.6)$ & $13(100)$ \\
\hline
\end{tabular}

A $50 \%$ fatality rate was recorded among neonates with different morbidities grouped as "others". However, for a specific morbidity, fatality rate was highest among neonates with jaundice (30.1\%) followed by prematurity and birth asphyxia with $26.4 \%$ and $25.2 \%$ respectively. The case fatality rate as it relates to other morbidities is as shown on Figure 1.

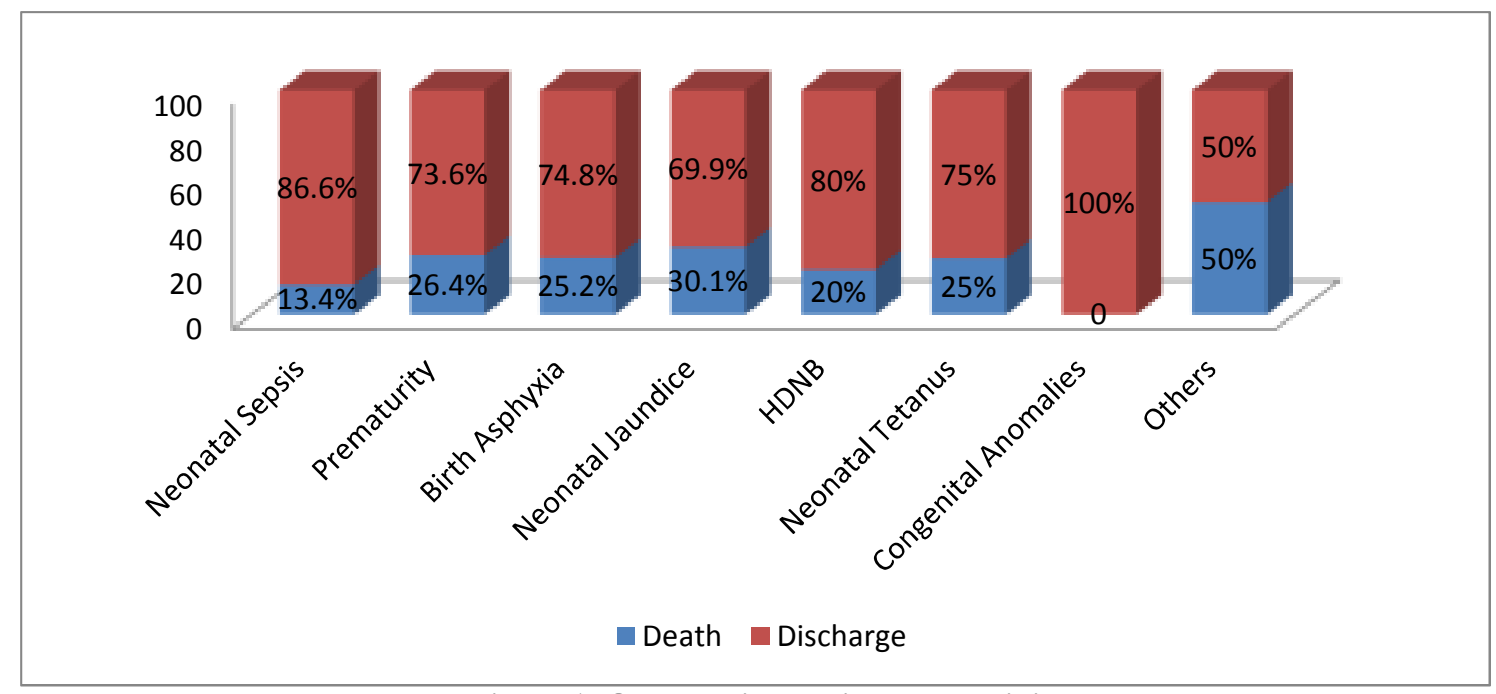

Figure 1: Outcome in relation to morbidity

\section{Discussion}

Most published studies on neonatal morbidity and mortality in the world have been done in newborn units and others are community based. However, in most secondary health care facilities across Nigeria, newborns are admitted into the general paediatric ward. However, activities that occur at this level of the health care delivery system rarely get published in journals. Thus it is difficult to find studies locally to which comparison could be made. This same challenge was encountered by Simiyu in Kenya when a similar study was carried out ${ }^{7}$. Available data on neonatal morbidity and mortality are from studies carried out in the newborn units of tertiary hospitals which have most of the equipment and specialist nursing personnel needed to optimally care for sick neonates.

In this study, about one fifth of paediatric medical admissions were newborns. Although lower than the $54.6 \%$ recorded in Jos University Teaching Hospital (JUTH $)^{5}$, it is still significant considering that our hospital does not have a newborn unit. The admission policy of the department where preterm infants weighing $<1500 \mathrm{~g}$ and those with severe congenital anomalies were referred could have contributed to the lower figure recorded.

More males were admitted during the study with a male to female ratio of $1.6: 1$. This is higher than the 1.1:1 reported by researchers in Jos and, Enugu $^{5,6}$. The reason for this difference is not clear. The biological susceptibility of the males to infections could be a reason for the male preponderance ${ }^{8}$.

The neonatal mortality recorded in this study $(20.3 \%)$ is similar to that observed by Ugwu et al in the newborn unit of Delta State University Teaching Hospital (DELSUTH) ${ }^{8}$, but marginally higher than that reported by Toma et al in Jos University Teaching Hospital (JUTH), and Ezechukwu et al in Nnewi ${ }^{4,6}$. Most deaths occurred in the first week of life, a trend established not only in Nigeria ${ }^{7,9}$. However, in this study, deaths in the first 24 hours following admission (59.4\%) was much higher than previously reported. This may be attributed to the late presentation of the newborns 
to the hospital, often occasioned by failure on the part of the caregiver to recognize subtle signs of disease. The average ages of the newborns at admission in this study was $5.7 \pm 5.9$ days. Our limited capacity in terms of equipment and personnel needed for intensive newborn care may also have contributed to higher mortality recorded in the first 24 hours.

Common morbidities in this study included neonatal sepsis, prematurity, birth asphyxia, neonatal jaundice, haemorrhagic disease of the newborn and neonatal tetanus. These morbidities have been reported in other studies across the developing world..$^{5,8,9}$. Strikingly, haemorrhagic disease of the newborn was a significant cause of neonatal admissions in this study. This could have resulted from the practice in most hospitals and clinics around study location of not administering prophylactic Vitamin K to newborns at delivery.

Neonatal sepsis was the commonest morbidity necessitating admission. This has been documented in other studies ${ }^{3-6}$. The prevalence in this study was $43.3 \%$ which is higher than the $34.4 \%$ reported by Toma et al in JUTH, $25.7 \%$ by Ugwu in DELSUTH, $17 \%$ by Ekwochi et al. The higher prevalence in our study may be attributable to the out born status of almost $80 \%$ of the study population. The environmental conditions in which some of these deliveries take place are unhygienic, cord care practices by mothers are also less than optimal and there is also failure to recognize risk factor for sepsis. In spite of this high burden, the case fatality rate in our study was low (13.4\%) which is consistent with findings of other studies ${ }^{6,7}$.

Prematurity was a common cause of admissions in this study only second to neonatal sepsis even though only newborns more than $1500 \mathrm{~g}$ were admitted as per unit policy. In the developed world, the challenges of premature infants have been to a large extent surmounted with the use of cutting edge technology in the field of neonatology ${ }^{10,11}$. However, the reverse is the case in our locality. It is therefore not surprising that in this study prematurity had a case fatality rate of $26.4 \%$.

Neonatal jaundice had the highest case fatality rate in this study $(30.1 \%)$ even though it was only responsible for $12.3 \%$ of the total neonatal admissions. This is in contrast to findings of other studies where the case fatality rate was less than $10 \% 5,6$. Most of the cases of neonatal jaundice seen during the study period presented very late, often with complications and co-morbidities such as bilirubin induced neurologic dysfunction (BIND), hypoglycaemia and infection. The knowledge and perception of newborn jaundice among the mothers in the area is very poor. In a recent study, only
$5.2 \%$ of the mothers interviewed knew the correct treatment for neonatal jaundice. Majority of the mothers still consider exposure to sunlight, the use of oral antibiotics and the use of herbal preparations as treatment options ${ }^{12}$. With such a high level of ignorance amongst the people it is not unexpected to find a high case fatality rate.

Inevitably, newborns are still being treated and will continue to be treated in the general paediatric ward of most secondary health care facilities. Our mortality rate was comparable to figures in some newborn units of tertiary hospitals. This may have been due to certain measures taken by the unit, including reserving an area on the ward with eight cots for neonates alone, ensuring regular hand washing by staff and mothers, keeping babies warm with a 200 watts bulb about $50 \mathrm{~cm}$ from the baby and kangaroo mother care (KMC) for preterm babies.

In addition, some specific and simple measures proposed by the World Health Organisation (WHO) if implemented can reduce up to two-third newborn deaths especially for home deliveries. These include among others, home visitation by skilled health worker during the first week of a newborn's life. These visits are to help promote and support early breastfeeding, help to keep the newborn warm by $\mathrm{KMC}$, promote hygienic umbilical cord care, assess the baby for signs of serious health problems such as feeding problems, reduced activity, fever, fits, or difficulty with breathing. Others include encouraging timely vaccination according to national schedules ${ }^{13,14}$.

\section{Conclusions}

This study recorded $20.3 \%$ mortality and the leading causes of admissions were neonatal sepsis, prematurity, perinatal asphyxia, haemorrhagic disease of the newborn and neonatal jaundice.

\section{Acknowledgement}

We express our profound gratitude to the doctors and nursing staff in the unit during the study period.

\section{References}

1. Black RE, Cousen S, Johnson HL, Lawn JE, Rudon L, Bassani DG, et al. Global, regional and national causes of child mortality 2008: A systematic analysis. Lancet 2010; 9730: 1969-87. http://dx.doi.org/10.1016/S01406736(10)6 0549-1

2. Zupan J, Aahman E. Perinatal mortality for the year 2000: estimates developed by 
W.H.O. Geneva: World Health Organization 2005.

3. Ezechukwu C.C, Ugochukwu E.F, Egbuonu I, Chukwuka J.O. Risk factors for neonatal mortality in a regional tertiary hospital in Nigeria. Nigerian Journal of Clinical Practice 2004; 7(2): 50-2.

4. Eke C.B, Ezomike U.O, Chukwu B.F, Chinawa J.M, Korie F.C, Chukwudi N, Ukpabi I.K. Pattern of Neonatal mortality in a tertiary health facility in Umuahia, South East Nigeria. International Journal of Tropical Disease and Health 2014; 4(2): 136-146.

http://dx.doi.org/10.9734/IJTDH/2014/498 5

5. Toma B.O, Ige O.O, Abok I.I, Onwuanaku C, Abah R.O, Donli A. Pattern of neonatal admissions and outcome in a tertiary institution in north central Nigeria. Journal of Medicine in the Tropics 2013; 15(2): 121-5. http://dx.doi.org/10.4103/22767096.12359 0

6. Ekwochi U, Ndu I.K, Nwokoye O.U, Ezenwosu O.U, Amadi O.F, Osuorah D.I.C. Pattern of morbidity and mortality of newborns admitted into the sick and special care baby unit of Enugu State University Teaching Hospital, Enugu State. Nigerian Journal of Clinical Practice 2014; 17(3): 346-51. http://dx.doi.org/10.4103/11193077.13023 8

PMid: 24714015

7. Simiyu D.E. Morbidity and mortality of neonates admitted in general paediatric ward at Kenyatta National Hospital. East African Medical Journal 2003; 80(12): 611-6.

PMid: 15018416

8. Ugwu G.I.M. Pattern of morbidity and mortality in the newborn special care unit in a tertiary institution in the Niger Delta region of Nigeria: A two year prospective study. Global Advanced Research Journal of Medicine and Medical Sciences 2012; 1(6): 133-8.

9. Prasad V, Singh N. Causes of morbidity and mortality in neonates admitted in government medical college, Haldwaniin Kumaun Region, India. Journal of
Pharmaceutical and Biomedical Sciences 2011; 9: 1-4.

10. Blencowe H, Cousens S, Oestergaard M.Z Chou D, Moller A.B, Narwal R et al: National, regional and worldwide estimates of preterm birth rates in the year 2010 with time trends since 1990 for selected countries: a systematic analysis and implications. Lancet 2012; 379: 216272.

http://dx.doi.org/10.1016/S01406736(12)6 0820-4

11. Lawn J.E, Kinney M.V, Belizan J.M, Mason E.M, McDougall L, Larson J et al. Born too soon: Accelerating action for prevention and care of 15 million newborns born too soon. Reproductive Health 2013; 10(suppl1): S6 http://dx.doi.org/10.1186/1742-4755-10S1-S6

PMid: 24625252 PMCid: PMC3828574

12. Okposio M.M, Adebanjo E.O. Evaluation of knowledge and perception of newborn jaundice among parturient mothers in a secondary health care centre in the Niger Delta region of Nigeria. Bangladesh Journal of Medical Sciences 2014; 13(3): 292-7.

http://dx.doi.org/10.3329/bjms.v13i3.1652 1

13. Baqui A.T et al. Projahnmo Study Group. Effect of community- based newborn care intervention package implemented through two service delivery strategies in sylhet district, Bangladesh: a cluster-randomised controlled trial. Lancet 2008; 371(19628): 1936-44.

http://dx.doi.org/10.1016/S01406736(08)6 0835-1

14. Bhutta Z.A et al. implementing community based perinatal care: result from a pilot study in rural Pakistan. Bull World Health Organisation 2008; 86(6): 452-9.

http://dx.doi.org/10.2471/BLT.07.045849

PMid: 18568274 PMCid: PMC2647462 